\title{
Article \\ Subtyping on Live Lymphoma Cell Lines by Raman Spectroscopy
}

\author{
Klytaimnistra Katsara ${ }^{1,2}$, Konstantina Psatha ${ }^{1}$, George Kenanakis ${ }^{3}{ }^{\circledR}$, Michalis Aivaliotis ${ }^{1, t}+\ddagger$ \\ and Vassilis M. Papadakis ${ }^{1, *(1)}$
}

1 Institute of Molecular Biology and Biotechnology, Foundation for Research and Technology-Hellas, N. Plastira 100, GR-70013 Heraklion, Greece; klytaimnistra_katsara@imbb.forth.gr (K.K.); konstantina_psatha@imbb.forth.gr (K.P.); aivaliot@imbb.forth.gr (M.A.)

2 Department of Chemistry/Biochemistry Section, University of Crete, Andrea Kalokerinou, GR-71500 Heraklion, Greece

3 Institute of Electronic Structure and Laser, Foundation for Research and Technology-Hellas, N. Plastira 100, GR-70013 Heraklion, Greece; gkenanak@iesl.forth.gr

* Correspondence: vassilis_papadakis@imbb.forth.gr; Tel.: +30-28-1039-1267

+ Current address: Laboratory of Biochemistry, Department of Medicine, School of Health Sciences, Aristotle University of Thessaloniki, GR-54124 Thessaloniki, Greece.

$\ddagger$ Current address: Functional Proteomics and Systems Biology (FunPATh), Center for Interdisciplinary Research and Innovation (CIRI-AUTH), Balkan Center, GR-54124 Thessaloniki, Greece.

check for updates

Citation: Katsara, K.; Psatha, K.; Kenanakis, G.; Aivaliotis, M.; Papadakis, V.M. Subtyping on Live Lymphoma Cell Lines by Raman Spectroscopy. Materials 2022, 15, 546. https://doi.org/10.3390/ma15020546

Academic Editor: Francesco

Inchingolo

Received: 12 December 2021

Accepted: 9 January 2022

Published: 12 January 2022

Publisher's Note: MDPI stays neutral with regard to jurisdictional claims in published maps and institutional affiliations.

Copyright: (C) 2022 by the authors. Licensee MDPI, Basel, Switzerland. This article is an open access article distributed under the terms and conditions of the Creative Commons Attribution (CC BY) license (https:// creativecommons.org/licenses/by/ $4.0 /)$.

\begin{abstract}
Raman spectroscopy is a well-defined spectroscopic technique sensitive to the molecular vibrations of materials, since it provides fingerprint-like information regarding the molecular structure of the analyzed samples. It has been extensively used for non-destructive and label-free cell characterization, particularly in the qualitative and quantitative estimation of amino acids, lipids, nucleic acids, and carbohydrates. Lymphoma cell classification is a crucial task for accurate and prompt lymphoma diagnosis, prognosis, and treatment. Currently, it is mostly based on limited information and requires costly and time-consuming approaches. In this work, we are proposing a fast characterization and differentiation methodology of lymphoma cell subtypes based on Raman spectroscopy. The study was performed in the temperature range of $15-37^{\circ} \mathrm{C}$ to identify the best cell measurement conditions. The proposed methodology is fast, accurate, and requires minimal sample preparation, resulting in a potentially promising, non-invasive strategy for early and accurate cell lymphoma characterization.
\end{abstract}

Keywords: Raman spectroscopy; PCA; subtyping; cell lines; non-Hodgkin lymphoma; Hodgkin lymphoma; temperature

\section{Introduction}

Human lymphoma represents a diverse group of blood cancers emanating from lymph nodes [1]. There are two major categories of lymphoma: Hodgkin lymphoma (HL; B-cell origin) and Non-Hodgkin lymphoma (NHL; B-, T-, NK- cell origin) [2]. Under the microscope, $\mathrm{HL}$ are mainly distinguished from NHL by the presence of multinucleated Reed-Sternberg cells (RS cells). However, occasionally, RS cells with similar or identical morphology and phenotype are seen in both HL and NHL [3,4], posing significant diagnostic and therapeutic challenges.

Classical Hodgkin lymphoma (cHL) and mantle cell lymphoma (MCL) are both heterogeneous B-cell derived lymphomas, with distinctive clinical presentation, histological and molecular signatures. cHL, one of the two major categories of Hodgkin lymphoma (HL) accounting for approximately $30 \%$ of all lymphomas [5], is considered as a highly curable malignancy, however this is not the case for elderly patients [6]. Mantle cell lymphoma (MCL), a rare and typically aggressive form of NHL representing about $3-10 \%$ of adult-onset NHL in Western countries, is often diagnosed at a late stage during biopsy [7]. 
Therefore, improvements in early diagnosis will most likely advance cHL and MCL management and survival rate [8].

Raman spectroscopy is a promising, non-destructive label-free technique for the lymphoma cell early detection in the blood and its biochemical profile. It is a vibrational spectroscopy method, with proven applications in a variety of scientific fields for diagnostic purposes. Raman spectroscopy has been applied in cancer diagnosis $[9,10]$ in tissues, [11,12] and in cells [8]. Cell subtyping can further be supported by PCA which is a standard technique used in Raman spectroscopy [13]. Raman spectroscopy analysis and imaging of nucleus area in live HL and NHL cells could potentially provide more accurate and clear results in regard to the different lymphoma "fingerprinting", distinguishing different lymphoma subtypes [14].

Previously, scientists distinguished non-Hodgkin lymphoma B-cells from normal Bcells using Raman spectroscopy to demonstrate the unique fingerprint of each cell line [8]. B-NHL Burkitt's lymphoma cell lines (Ramos and CA46) were cultured and normal B-cells were isolated from peripheral blood. A Micro-Raman RXN system was used for the Raman measurements, whereby cells were placed directly on aluminum reflective slides cleaned with methanol before and after the measurements. Each measurement collected the Raman signal for $60 \mathrm{~s}$ with $10 \mathrm{~mW}$ laser power in the range from 600 to $1800 \mathrm{~cm}^{-1}$, providing the biological information concerning the cells' constituents. Raman spectroscopy analysis provided fingerprints for DNA/protein concentrations and saccharide bonds, which were difficult to distinguish. For this reason, principal component analysis (PCA) was performed to detect the differences between the cell types. In conclusion, the Raman spectroscopy fingerprints of normal B-cells and B-NHL cells had similar peaks and phenotypes, which could be assigned to cellular constituents (DNA/RNA, amino acids, lipids, carbohydrates).

Based on our knowledge and the available literature, a very limited number of studies have used Raman spectroscopy in lymphoma and there is no priori work on the analysis and comparison of HL and NHL using Raman spectral characteristics. This study focuses on comparing two model lymphoma cell lines (MDA-V/HL and JMP-1/MCL; NHL) to evaluate Raman spectroscopy as a tool for the differentiation of the two lymphoma subtypes, screening them for characteristic Raman shifts. Raman spectra were acquired from the intracellular nucleus area in live cells. Tests were performed under different temperatures, ranging from $15{ }^{\circ} \mathrm{C}$ to $37^{\circ} \mathrm{C}$, investigating the best cell measurement conditions and confirming that the proposed methodology can be applied under normal cell growth conditions $\left(37^{\circ} \mathrm{C}\right)$. Subsequently, principal component analysis (PCA) was used to detect the differences between the complex Raman signals. Results indicate that HL and NHL cell lines can be differentiated at room temperature.

\section{Materials and Methods}

\subsection{Cell Lines, Culture Conditions and Sample Preparation}

Two B-cell lymphoma cell lines harboring wild type p53 (wtp53), MDA-V/HL (cHL), and Epstein Barr virus ((EBV)-positive cHL) and JMP-1/MCL NHL (MCL) were used. Both cell lines were maintained under standard conditions of exponential growth, as described previously (RPMI 1640 medium supplemented with 15\% fetal bovine serum, (FBS), incubated at $37^{\circ} \mathrm{C}$ in a $5 \% \mathrm{CO}_{2}$ humidified atmosphere) [15]. Cell viability (>90\%) was assessed using Trypan blue staining prior to Raman measurements. Cells were washed with phosphate buffered saline (PBS), re-suspended in phenol-free RPMI 1640, and 100,000 cells were used for further analysis, where $20 \mu \mathrm{L}$ of the resulting cell suspension was placed directly on a clean $\mathrm{CaF}_{2}$ microscope slide.

A schematic of the procedure followed during live cell Raman spectroscopy analysis is depicted in Figure 1. 


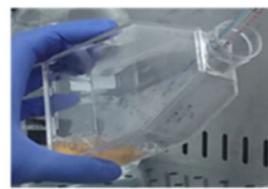

Lymphoma cells in phenol-red medium

Final cells $10^{5} \mathrm{cells} / \mathrm{ml}$

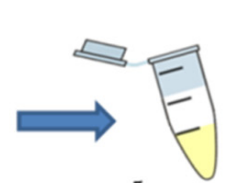

$5 \times 10^{5}$ cells $/ \mathrm{ml}$

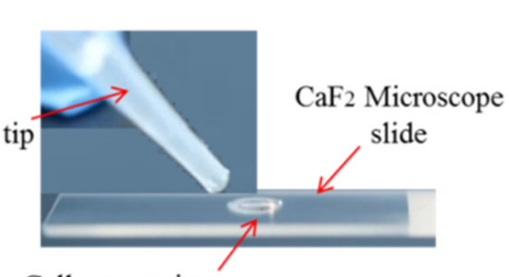

Cell suspension

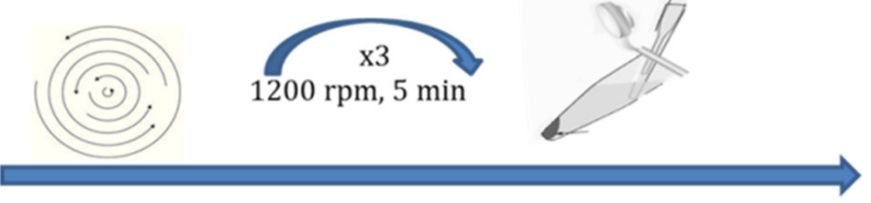

Discard supernatant; resuspend in PBS/phenol-free medium

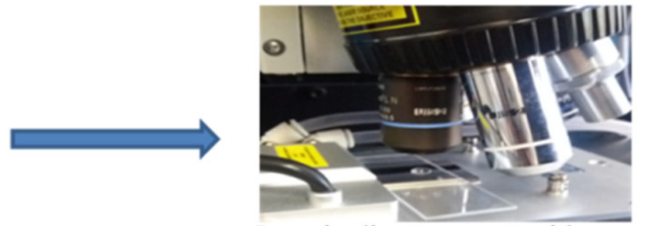

Lens in direct contact with sample

Figure 1. Sample preparation process.

The measured cells, had a diameter approximately of: $10-25 \mu \mathrm{m}$ for the MDA-V/HL, and 12-14 $\mu \mathrm{m}$ for the JMP-1/MCL cell lines.

All sample preparation was performed under a ducted fume hood with ventilation to outside, which provides the most user protection mostly for chemically dangerous fumes, and close to the Raman microscope a Biological Safety Cabinet (BYKG-I, Biobase, Shandong, China), enhanced with UV lamp for sterilization, suitable for work involving low to moderate risk agents (Biosafety Levels 1, 2 and 3). Unlike a conventional fume hood, the HEPA filter in the Class I Biosafety Cabinet protects the environment by filtering air before it is exhausted, while with the negative pressure, personnel protection is made possible by constant movement of air into the work area. As a result, the "BIOBASE BYKG-I" Class I Biological Safety Cabinet provides protection for the user and surrounding environment, but no protection for the sample being manipulated.

\subsection{Instrument and Measurement Preparation}

Raman measurements were performed using a modified LabRAM HR Raman Spectrometer from HORIBA Scientific.

\subsubsection{Instrument Description}

LabRAM HR Raman Spectrometer (HORIBA Scientific, Lille, France) is a confocal Raman microscope. The Raman excitation laser line had a central wavelength at $532 \mathrm{~nm}$ and a laser output power of $\sim 100 \mathrm{~mW}$. The objective lens used was an Olympus $60 \times$ water immersion lens with a numerical aperture (NA) of 1.2 and a working distance of $280 \mu \mathrm{m}$ (UPLSAPO60XW/1.2, Olympus), which was in direct contact with the sample. The resulting maximum laser power $(100 \%)$ on the sample under the aforementioned setup was measured to be $32 \mathrm{~mW}$ with a laser spot of $0.7 \mu \mathrm{m}(0.54 \mu \mathrm{m}$ in theory), with an axial length about $0.6 \mu \mathrm{m}(0.47 \mu \mathrm{m}$ in theory). A grating of 600 groves $/ \mathrm{mm}$ was used that resulted to a Raman spectral resolution of around $1 \mathrm{~cm}^{-1}$. The Raman signal detector was the Syncerity CCD Deep Cooled Camera by Horiba, operating at $-50^{\circ} \mathrm{C}$. A temperature-controlled stage PE120-XY (Linkam, Tadworth, United Kingdom) was coupled with the microscope stage to ensure the sample's temperature control and stability. This stage incorporates a PT100 temperature sensor (Linkam, Tadworth, United Kingdom), that provides feedback to the controller, achieving control and stability in temperature of $+/-0.1{ }^{\circ} \mathrm{C}$.

Instrument calibration was performed before each experiment. Spectral calibration was performed with a Si reference sample, presenting a single peak at $520.7 \mathrm{~cm}^{-1}$. Validation of the spectral calibration was further achieved with the substrate used for the samples, which was a Raman grade $\mathrm{CaF}_{2}$ microscopic slide obtained by Crystran, which has a single 
Raman peak at $321 \mathrm{~cm}^{-1}$. The substrate Raman spectrum was tested, and no other Raman peaks appeared following the same experimental conditions.

\subsubsection{Acquisition Settings}

The microscope was setup to acquire Raman signals in the spectral range between 300 and $3150 \mathrm{~cm}^{-1}$, which corresponds to two spectral windows with the current grating. Laser operated at maximum intensity $(100 \%)$. Measurements were acquired in the center of each cell (nucleus). Acquisition time was set to $5 \mathrm{~s}$ with a spectral accumulation of 3 spectra/point. This resulted to a total acquisition time of around $40 \mathrm{~s}$ per point. These acquisition settings were tested before the experiment to ensure that cells were not visibly damaged by the laser power during the exposure of $40 \mathrm{~s}$, through the bright-field microscope.

\subsubsection{Measurement Process}

$20 \mu \mathrm{L}$ of cell's suspension was transferred from the Eppendorf tube to the $\mathrm{CaF}_{2}$ substrate. The water immersion lens was in direct contact with the cell suspension, achieving maximum efficiency of the Raman spectrum measurement. A relaxation time of approximately 5 min was allowed, for temperature stabilization and for the cells to sink and relax on the substrate surface. When the objective lens focused in the middle of each cell, it created a thin layer of cell suspension of approximately $300 \mu \mathrm{m}$ thickness between the substrate's surface and the objective lens.

From each cell, one measuring point was observed, being the center of the cell, aiming at the cell nucleus. It is worth noting that, following each measurement, a second measurement was acquired, being the surrounding area of the cells, which was used for background subtraction.

Following each measurement, we used a cleaning solution of $85 \%$ n-hexan and $15 \%$ isopropyl alcohol to clean the objective lens and ethanol for all the microscopic slides before proceeding to the next measurement. The users wore gloves and FFP2/N95 masks when handling the samples. The remaining samples were sent back to the laboratory for proper treatment to be discarded.

\subsubsection{Experiments Performed}

Raman measurements of lymphoma cells were performed always monitoring temperature, keeping it constant during acquisition. Cell measurements were performed at six different temperatures $\left(37,30,25,20,18,15^{\circ} \mathrm{C}\right)$. The temperature range was selected based on the higher and lower limits set for this experiment. The upper limit corresponded to the normal physiological temperature cells thrive at $\left(\mathrm{T}=37^{\circ} \mathrm{C}\right)$. The lower limit $\left(\mathrm{T}=18^{\circ} \mathrm{C}\right)$ was the temperature where the threshold existed between liquidation of the environmental humidity and evaporation. The temperature range between these two limits was covered in steps of $5^{\circ} \mathrm{C}\left(\mathrm{T}=30^{\circ} \mathrm{C}, 25^{\circ} \mathrm{C}\right.$, and $\left.20^{\circ} \mathrm{C}\right)$. Since $\mathrm{T}=35^{\circ} \mathrm{C}$ was very close to the upper limit, it was excluded from the temperature list. $\mathrm{T}=15^{\circ} \mathrm{C}$ was used as an extra temperature value to test Raman signals and cell viability.

Four independent experiments were performed, with two biological repeats for every cell line (BRx), and with $x$ defining the number of the experiment. BR1 and BR2 correspond to JMP-1/MCL NHL cell measurements. In BR1, cells were measured under 37, 30, 18, and $15{ }^{\circ} \mathrm{C}$ temperatures. In BR2, cells were measured under $30,25,20$, and $15^{\circ} \mathrm{C}$ temperatures. $\mathrm{BR} 3$ and BR4 refer to MDA-V/HL cell measurements. In BR3, cells were measured under $37,30,25,20,18$, and $15{ }^{\circ} \mathrm{C}$ temperatures. In BR4, cells were only measured under $15^{\circ} \mathrm{C}$. Data from all four experiments under all temperatures were included in the final analysis.

\subsubsection{Raman Spectral Database}

Through the analysis of the Raman signals and the peaks identified, a database was constructed from information derived from literature in order to translate Raman spectral findings to biological information [16-18]. The constructed database with the Raman peaks 
and related assignments can be found in Table S1. Raman peak assignments selected included both nucleus and nuclear membrane information, since our detection volume could have interfering signals from both. Nucleus houses nucleic acids (DNA/RNA), proteins, phospholipids, various phosphate compounds, and several inorganic compounds. The nucleus is surrounded by a nuclear membrane, which consists of phospholipids and proteins (forming nuclear pores). In the left column of the table, we present the Raman peak wavenumber. When a temperature dependence was observed in the Raman peaks, an asterisk was placed next to the corresponding wavenumber for discrimination. In the second column, the Raman peak assignments are presented. Additionally to the asterisk, a color coding (red color) is used to indicate the temperature-based Raman peaks and assignments.

\subsection{Raman Spectra Processing and Analysis}

Raw Raman spectral data acquired from the Raman microscope underwent the following processing methodology: (a) cosmic rays were removed by an internal function Despike (LabSpec LS6, Horriba); (b) background signal was acquired from the cell suspension in the neighborhood area outside of the cell; (c) background signal was subtracted from the raw Raman spectral data. A typical example of this process can be found in the supporting (Figure S1). No further processing (smoothing, or noise cancellation processing) was performed in the Raman spectral data to ensure minimum effect in the analysis.

Due to the size of our experimental data, principal component analysis was chosen as a potential unsupervised discrimination methodology of the cellular populations. This is the standard technique used for discrimination approaches [19]. We could not perform supervised approaches like (PLS-DA), particularly given that the requirement for the training data would lead to a highly undertrained model [20]. In the case of a significantly larger data set, in the range of hundreds, PLS-DA would be one good methodology for this analysis, and to potentially examine the effectiveness of other multivariate classification techniques that could lead to cell line classification.

PCA was performed using a tool (Raman PCA Tool, by Patrizio Candeloro [21]) publically available through (access date: 17 November 2021, https:/ / sourceforge.net/ projects/ramantoolset/), for the comparison of HL and NHL cells, but also for comparison between the different experiments (BR). When we carry out a PCA analysis, our aim is to find the principal component spectral characteristics which indicate the greatest differentiation and/or clustering among the selected samples.

\section{Results and Discussion}

A full Raman Spectrum (300-3150 $\mathrm{cm}^{-1}$ ) was acquired from a total number of 60 live cells from two distinct lymphoma cell lines (JMP-1/MCL; NHL and MDA-V/HL). In this experiment, we measured various points (cell nucleus, cell cytoplasm, cell membrane, and extracellular space). Raman signals from the nucleus area gave us distinct peaks that were strongly repeatable, and we can be certain that they correspond to cell variations. As discussed in the experimental section, our experimental procedure had a spot size of approximately $0.8 \mathrm{um}$, which is significantly larger than the cell membrane dimensions $(\sim 50 \mathrm{~nm})$. This caused significant signal interference deriving from the cytoplasm and/or the extracellular space. Further, measurements in the membrane as well as in the cytoplasm were affected by the cell's mobility, causing more interference with either membrane or nucleus. This resulted in measurements with low repeatability, so we decided to exclude them from this work. Concluding, Raman signals acquired from the nucleus area presented high repeatability that we could trust, so we used only those to compare and analyze the differences between JMP-1/MCL, NHL, and MDA-V/HL cells. Raman spectral data were processed as described in Section 2. Hence, we show that there is a distinct differentiation between the Raman signals extracted from the nuclei of the two cell lines. 


\subsection{JMP-1/MCL NHL and MDA-V/HL Cell Lines Comparison}

The comparison of JMP-1/MCL NHL and MDA-V/HL cell lines was performed for all experiments (BR1, BR2, BR3, BR4)

In Figure 2, the PCA plot, the average Raman spectra, and the associated Raman spectral differences are depicted, deriving from the total number of cells measured in our experiments.
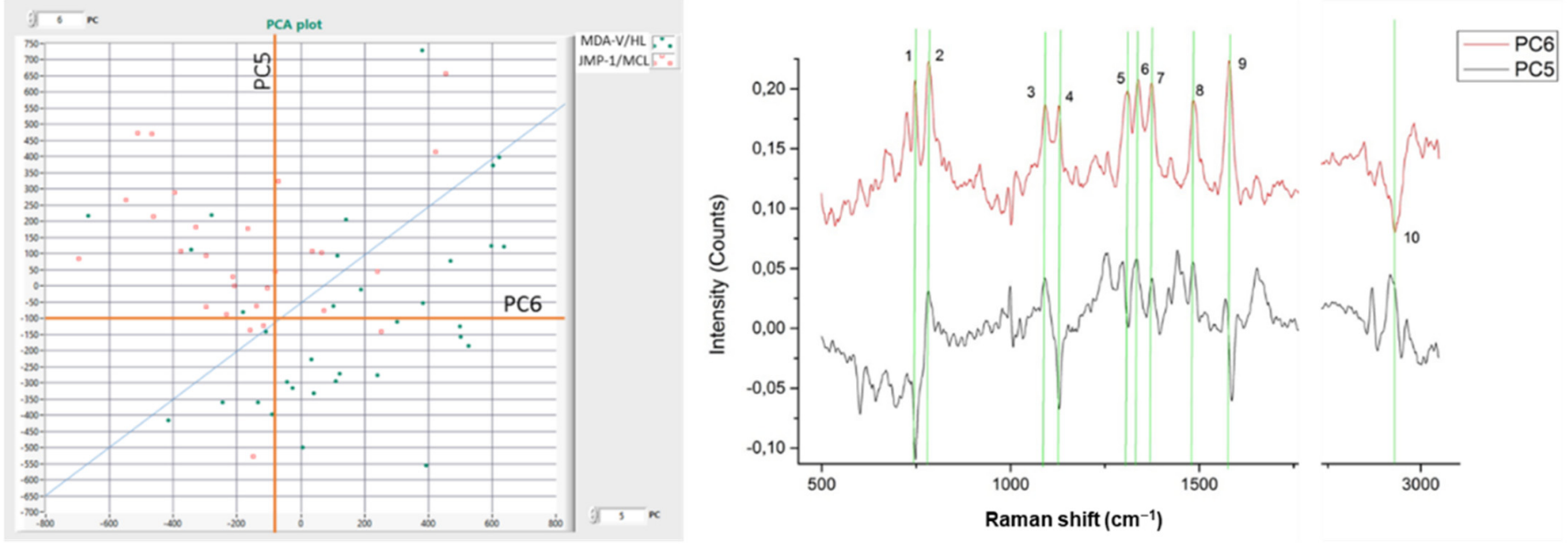

Figure 2. (left) Comparison $(n=60)$ between MDA-V/HL and JMP-1/MCL NHL cell lines; (right) PC Raman spectra showing the cell lines spectral differences.

In particular, from the PCA plot, we see that PC5 separates the cell lines with a cell differentiation efficiency (CDE) of $71.66 \%$, and PC6 with a CDE of $68.33 \%$, resulting in a higher CDE of $81.66 \%$ when both PCs (5 and 6) are taken into account.

From the resulting PCs (PC5 and PC6), we calculated their spectral curves and identified the major peaks and common lines that are responsible for the differentiation of the two cell lines. These findings are depicted with a green line in Figure 2, and their value is presented in Table 1. This table shows the common line wave numbers and their assignments from the Raman spectral database.

In Figure 2, it is shown that the cell differentiation has a CDE of $81.66 \%$.

As described in the experimental process we mainly performed measurements at $15{ }^{\circ} \mathrm{C}$. Raman peak differences affected by the temperature changes were identified and described in the related section. Further, to better understand if the CDE was affected by other parameters except the cell lines subtype differences, we tested three different hypotheses based on the individual experimental BR we performed. Initially, we tested if the two (BR1 vs. BR2) that involve the same cell line type differ, and second if the two (BR1 vs. BR3, 4) and (BR2 vs. BR3, 4) present different CDE. Table 1 presents the most important signaling differences between HL and NHL lymphoma cell lines. The Raman peaks that are affected by temperature are highlighted (in red color and with a superscript). As it is shown, six out of 10 of the major Raman peaks are not affected by temperature. This fact is important since it can support the hypothesis that cell subtyping can be performed independently of the temperature allowing measurements in room temperatures.

Additionally, we repeated the PCA by performing three main processing tasks for better differentiation between the two cell lines. The first processing was to correct the baseline with a polynomial function. The second processing was mean centering and the third was to perform variance adjustment. Results showed no significant improvement on the differentiation between the two cell lines. The results from this PCA are presented in Figures S2 and S3. As expected, due to the high variance between each data set, the mean centering did not affect the results as much. The fact that PC5 and PC6 indicate potential discrimination of the cell lines, in both analyses, indicates that the coherent differences are 
very small, though potentially significant, as such enabling unsupervised analysis. Thus, we considered using the data that were background subtracted and not baseline corrected as it may help shoulder peaks to have better significance.

Table 1. Most important Raman signaling differences between HL/cHL and MCL/NHL lymphoma cell lines, with the central wavelength of the Raman peaks and the related assignments. Red color and asterisk superscript correspond to the temperature-dependent Raman peaks.

\begin{tabular}{|c|c|c|c|}
\hline No & PC6 Peaks $\left(\mathrm{cm}^{-1}\right)$ & PC5 Peaks $\left(\mathrm{cm}^{-1}\right)$ & Assignment \\
\hline 1 * & 747 & 748 & $\begin{array}{l}747 \mathrm{~cm}^{-1} \rightarrow \mathrm{CH}_{2} \text { rocking, L-Phenylalanine [22], } 748 \mathrm{~cm}^{-1} \rightarrow \\
\text { DNA, ring breathing of pyrimidine of T [23] }\end{array}$ \\
\hline 2 & 783 & 782 & Phosphodiester, Cytosine, Thymine, Uracil \\
\hline 3 & 1091 & 1091 & $\begin{array}{l}1090 \mathrm{~cm}^{-1} \rightarrow \text { Symmetric phosphate stretching vibrations, } \\
1092-1093 \mathrm{~cm}^{-1} \rightarrow \text { Phosphodioxy }\end{array}$ \\
\hline $4^{*}$ & 1127 & 1129 & $\begin{array}{l}\left.\mathrm{v}(\mathrm{C}-\mathrm{N}) \text { stretching (lipids, } 1127 \mathrm{~cm}^{-1} \rightarrow \text { proteins }\right), v(\mathrm{C}-\mathrm{C}) \text { skeletal } \\
\text { of acyl backbone in lipid }\left(1129 \mathrm{~cm}^{-1} \rightarrow \text { trans conformation }\right)\end{array}$ \\
\hline 5 & 1310 & 1312 & $\begin{array}{l}1309 \mathrm{~cm}^{-1} \rightarrow \mathrm{CH}_{3} / \mathrm{CH}_{2} \text { twisting or bending mode of } \\
\text { lipid/collagen, } 1313 \mathrm{~cm}^{-1} \rightarrow \mathrm{CH}_{3} \mathrm{CH}_{2} \text { twisting mode of } \\
\text { collagen/lipid }\end{array}$ \\
\hline $6^{*}$ & 1337 & 1334 & $\begin{array}{l}1334 \mathrm{~cm}^{-1} \rightarrow \text { DNA/RNA purine bases, Guanine, Adenine), } \\
\text { proteins }\left(1337 \mathrm{~cm}^{-1} \rightarrow \text { amide III, } \mathrm{CH}_{2} \text { wagging vibrations from }\right. \\
\text { Glycine backbone and proline side chain, L-Histidine, } \\
\text { L-Tryptophane, L-Glutamate) }\end{array}$ \\
\hline 7 & 1373 & 1375 & $\begin{array}{l}\text { T, A, G (ring breathing modes of the DNA/RNA bases), Acetyl } \\
\text { coenzyme A [22] }\end{array}$ \\
\hline 8 & 1484 & 1484 & $\begin{array}{l}1480-1575 \mathrm{~cm}^{-1} \rightarrow \text { Amide II (largely due to a coupling of C-N } \\
\text { stretching and in-plane bending of the N-H group } \\
1485 \mathrm{~cm}^{-1} \rightarrow \mathrm{G}, \mathrm{A} \text { (ring breathing modes in the DNA bases) } \\
\text { Nucleotide acid purine bases (guanine and adenine), Purine rings } \\
\text { (guanine) [24] } \\
1483 \mathrm{~cm}^{-1} \rightarrow \mathrm{CG} \text { (C4 me) associated with } \mathrm{CH}_{2} \text { and } \mathrm{CH}_{3} \text { bending } \\
\text { and stretching vibrations, CG (C4 me) [24] }\end{array}$ \\
\hline $9 *$ & 1578 & 1586 & $\begin{array}{l}1586 \mathrm{~cm}^{-1} \rightarrow \mathrm{DNA} / \mathrm{RNA}, 1578 \mathrm{~cm}^{-1} \rightarrow \text { Guanine (N3), Guanine, } \\
\text { adenine }\end{array}$ \\
\hline 10 & 2928 & 2919 & $\mathrm{CH}_{2}$ asym stretches and $\mathrm{CH}$ stretches in lipids and proteins \\
\hline
\end{tabular}

\subsection{Comparison of Experiments BR1 vs. BR2 of JMP-1/MCL NHL Cell Line}

This analysis showed that the two cell lines had a low CDE. In particular, the best CDE was achieved under PC1 (Figure 3), where differentiation occurred in four Raman peaks (Table 2) and mainly in the peak of $2938 \mathrm{~cm}^{-1}$. In all other PCs, the CDE was lower than $50 \%$.

As a result, we conclude that there is no clear separation found between BR1 and BR2 at the Raman peaks identified as important for the cell lines differentiation described in Table 1.

The average Raman spectra from BR1 and BR2 experiments are presented in Figure S4. Further, the major Raman peaks identified from the PCA are presented in the following Table 2.

Comparing the Raman spectral differences of BR1 and BR2 identified in Table 2 with the Raman peaks identified as important for the differentiation of the cell lines described in Table 1, we see that the four Raman peaks in Table 2 are not significant for the cell differentiation. 

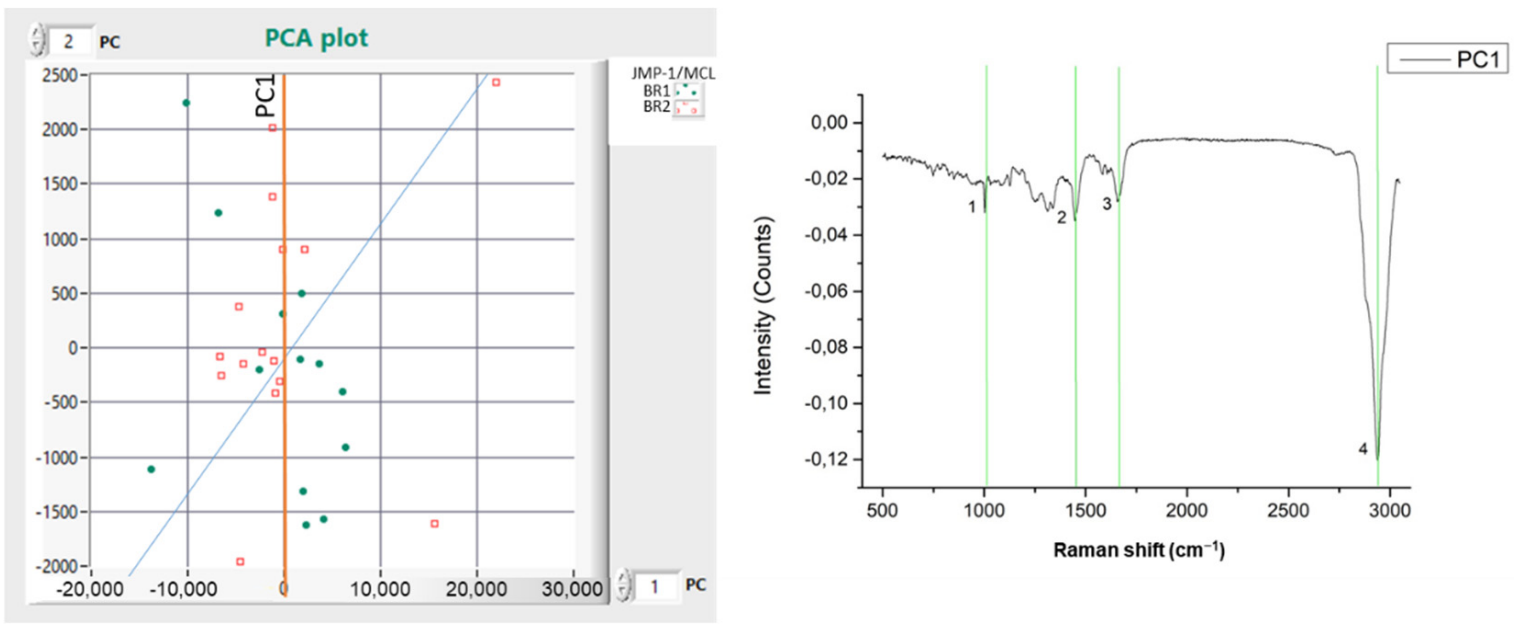

Figure 3. (left) PCA plot between measurements of two distinct experimental periods of from the same cell line. Green is BR1, Red is BR2 (JMP-1/MCL NHL); (right) PC Raman spectra showing the cell line differences.

Table 2. Major Raman peaks found in PC1 between BR1 and BR2 analysis.

\begin{tabular}{ccc}
\hline No & PC2 Peaks $\left(\mathbf{c m}^{-1}\right)$ & \multicolumn{1}{c}{ Assignment } \\
\hline 1 & 1002 & Proteins, $\mathrm{C}-\mathrm{C}$ aromatic ring stretching (collagen assignment) \\
\hline 2 & 1447 & $\begin{array}{l}\mathrm{CH}_{2} \text { bending mode of proteins and lipids, } \mathrm{CH}_{2} \text { deformation } \\
(\text { protein vibration), a marker for protein concentration, } \delta \text { as } \\
\left(\mathrm{CH}_{3}\right) \delta\left(\mathrm{CH}_{2}\right) \text { of proteins }\end{array}$ \\
\hline 3 & 1655 & Proteins, Lipids, $v(\mathrm{C}=\mathrm{O})$ amide $\mathrm{I}, \alpha$-helix, $\mathrm{C}=\mathrm{C}$ lipid stretch \\
\hline 4 & 2938 & $\mathrm{CH}_{2}$ asym stretches and $\mathrm{CH}$ stretches in lipids and proteins \\
\hline
\end{tabular}

3.3. Subtyping BR1 vs. BR3, BR4 (JMP-1/MCL NHL vs. $M D A-V / H L)$

As presented in Figure 4, we see that the two cell lines are separated with a CDE of $77.27 \%$.
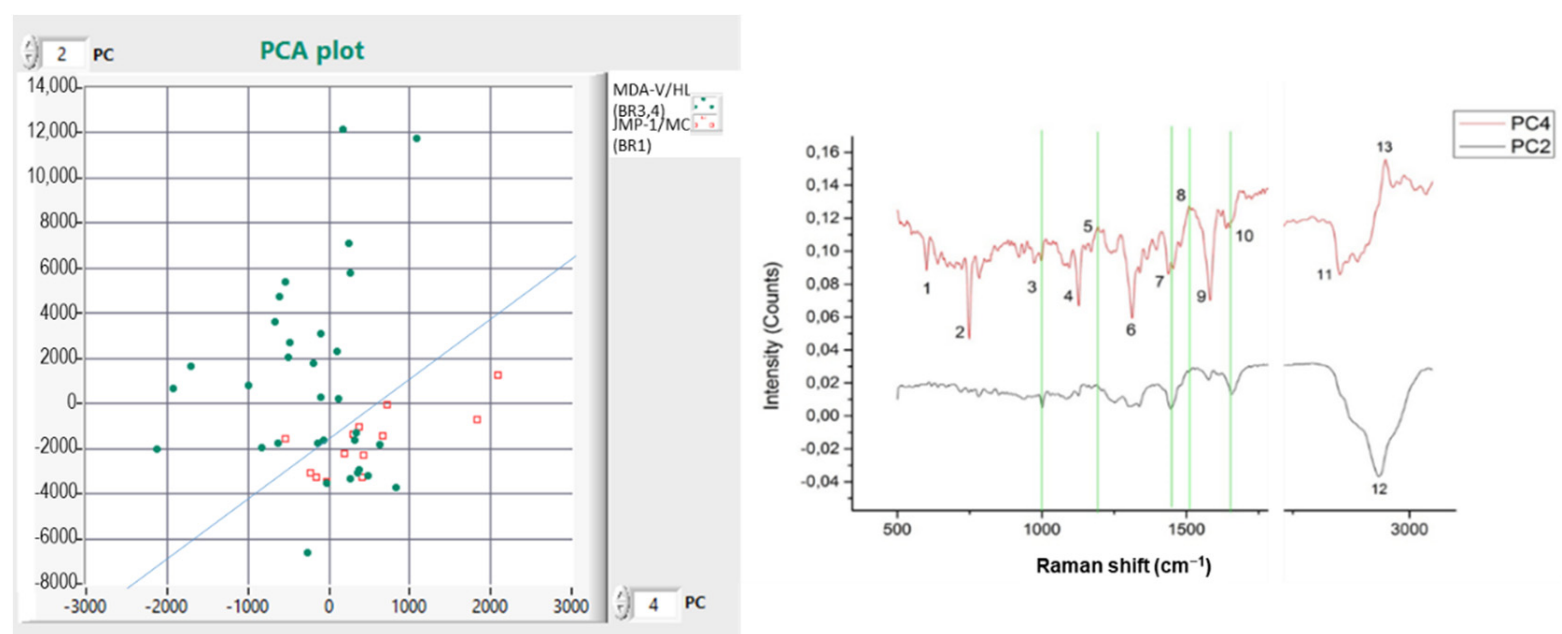

Figure 4. (left) Comparison between experiments BR1 (JMP-1/MCL NHL) and BR3,4 (MDA-V/HL) cell lines; (right) PCA Raman spectra showing the cell lines differences.

Further, the major Raman peaks identified are presented in Table 3. 
Table 3. Major Raman peaks found in PCA between BR1 and BR3, 4. In red color and with an asterisk superscript the temperature dependent Raman peaks are presented.

\begin{tabular}{|c|c|c|c|}
\hline No & PC4 Peaks $\left(\mathrm{cm}^{-1}\right)$ & PC2 Peaks $\left(\mathrm{cm}^{-1}\right)$ & Assignment \\
\hline 1 & 601 & - & Nucleotide conformation \\
\hline $2 *$ & 749 & - & $749 \mathrm{~cm}^{-1} \rightarrow$ Symmetric breathing of tryptophan \\
\hline 3 & 999 & 1001 & $\begin{array}{l}999 \mathrm{~cm}^{-1} \rightarrow v_{45}(\mathrm{C}-\mathrm{C}), \text { observed in the spectra of single human } \\
\text { Red blood cell }(\mathrm{RBC}), 1001 \mathrm{~cm}^{-1} \rightarrow \text { Symmetric ring breathing } \\
\text { mode of phenylalanine }\end{array}$ \\
\hline 4 * & 1127 & - & $\mathrm{v}(\mathrm{C}-\mathrm{N})$ stretching (proteins) \\
\hline 5 & 1194 & 1191 & $\begin{array}{l}1191 \mathrm{~cm}^{-1} \rightarrow \text { L-Valine, acetoacetate, } 1194 \mathrm{~cm}^{-1} \rightarrow \text { L-Proline [22], } \\
1185-1300 \mathrm{~cm}^{-1} \rightarrow \text { Antisymmetric phosphate vibrations }\end{array}$ \\
\hline 6 & 1312 & - & $1313 \mathrm{~cm}^{-1} \rightarrow \mathrm{CH}_{3} \mathrm{CH}_{2}$ twisting mode of collagen/lipid \\
\hline 7 & 1446 & 1445 & $\begin{array}{l}\delta\left(\mathrm{CH}_{2}\right), \delta\left(\mathrm{CH}_{3}\right) \text { protein (collagen) and lipid (phospholipids) } \\
\text { assignment }\left(\mathrm{CH}_{2} \text { bending mode being of diagnostic significance), }\right. \\
\mathrm{CH}_{2} \text { deformation }\left(1446 \mathrm{~cm}^{-1}\right)\end{array}$ \\
\hline 8 & 1509 & 1502 & $\begin{array}{l}1499 \mathrm{~cm}^{-1} \rightarrow \text { C-C stretching in benzenoid ring, } 1510 \mathrm{~cm}^{-1} \rightarrow \\
\text { Cytosine, A (ring breathing modes in the DNA bases }\end{array}$ \\
\hline $9 *$ & 1582 & - & $\mathrm{C}=\mathrm{C}$ stretching in Phenylalanine, hydroxyproline \\
\hline 10 & 1650 & 1656 & $\begin{array}{l}1650 \mathrm{~cm}^{-1} \rightarrow \text { amide } \mathrm{I}(\mathrm{C}=\mathrm{C}) \text { absorption, } 1656 \mathrm{~cm}^{-1} \rightarrow \text { cis } \\
\text { phospholipids, Carbonyl stretch }(\mathrm{C}=\mathrm{O})\end{array}$ \\
\hline 11 & 2851 & - & $\mathrm{CH}_{3}$ symmetric stretch of lipids \\
\hline 12 & - & 2934 & $\begin{array}{l}2934 \mathrm{~cm}^{-1} \rightarrow \mathrm{CH}_{2} \text { asym stretches and } \mathrm{CH} \text { stretches in lipids } \\
\text { and proteins }\end{array}$ \\
\hline 13 & 2949 & - & $\mathrm{CH}_{3}$ stretching vibrations \\
\hline
\end{tabular}

\subsection{Subtyping BR2 vs. BR3,4 (JMP-1/MCL NHL vs. $M D A-V / H L)$}

As presented in Figure 5, we see that the two cell lines are separated with a CDE of $81.25 \%$.
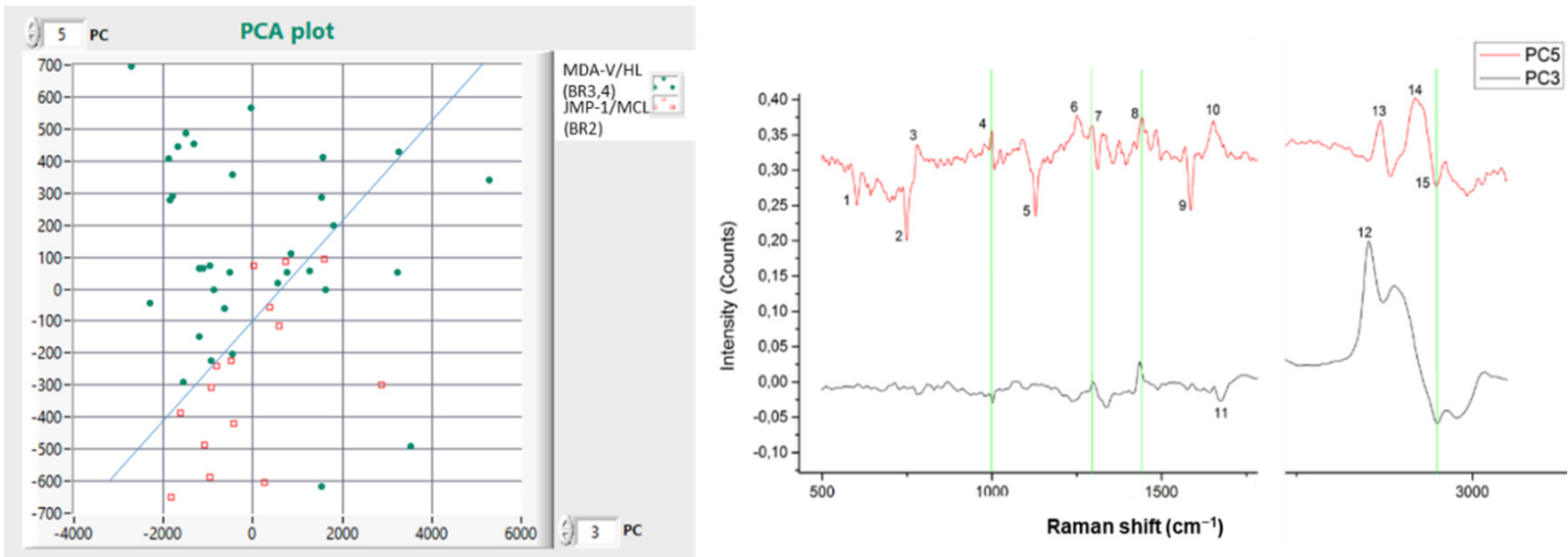

Figure 5. (left) Comparison between experiments BR2 (JMP-1/MCL NHL) and BR3,4 (MDA-V/HL) cell lines; (right) PCA Raman spectra showing the cell lines differences.

Further, the Raman peaks were found and are presented in Table 4. 
Table 4. Major Raman peaks found in PCA between BR2 and BR3, 4. In red color and with an asterisk superscript the temperature dependent Raman peaks are presented.

\begin{tabular}{|c|c|c|c|}
\hline No & PC5 Peaks $\left(\mathrm{cm}^{-1}\right)$ & PC3 Peaks $\left(\mathrm{cm}^{-1}\right)$ & Assignment \\
\hline 1 & 602 & - & Nucleotide conformation \\
\hline $2 *$ & 749 & - & Symmetric breathing of tryptophan \\
\hline 3 & 779 & - & DNA/RNA \\
\hline 4 & 999 & 1000 & $\begin{array}{l}900 \mathrm{~cm}^{-1} \rightarrow v_{45}(\mathrm{C}-\mathrm{C}), \text { observed in the spectra of single human } \\
\text { Red blood cell }(\mathrm{RBC}), 1000 \mathrm{~cm}^{-1} \rightarrow \text { Phenylalanine, Bound and } \\
\text { free NADH }\end{array}$ \\
\hline $5 *$ & 1129 & - & $v(C-C)$ skeletal of acyl backbone in lipid $\rightarrow$ trans conformation \\
\hline 6 & 1251 & - & Guanine, cytosine $\left(\mathrm{NH}_{2}\right)$ \\
\hline 7 & 1298 & 1298 & $\begin{array}{l}1220-1300 \mathrm{~cm}^{-1} \rightarrow \text { Amide III (arising from coupling of C-N } \\
\text { stretching \& N-H bonding-can be mixed with vibrations of side } \\
\text { chains), amide III (L-Arginine [22]), CH bend in Lipids (Palmitic } \\
\text { acid), Acyl chains }\end{array}$ \\
\hline 8 & 1441 & 1435 & $\begin{array}{l}1435 \mathrm{~cm}^{-1} \rightarrow \text { Thymine (weak) [22], } 1420-1481 \mathrm{~cm}^{-1} \rightarrow \\
\text { DNA/RNA, Guanine, Adenine, } 1441 \mathrm{~cm}^{-1} \rightarrow \mathrm{CH}_{2} \text { scissoring } \\
\text { and } \mathrm{CH}_{3} \text { bending in lipids, Cholesterol and its esters, } \mathrm{C}-\mathrm{H} \\
\text { bending mode of accumulated lipids in the vecrotic core of the } \\
\text { atheromatous plaque }\end{array}$ \\
\hline $9 *$ & 1586 & - & DNA/RNA \\
\hline 10 & 1653 & - & $1653 \mathrm{~cm}^{-1} \rightarrow$ Lipid (C=C stretch, Ascorbic acid [22]) \\
\hline 11 & - & 1672 & $\begin{array}{l}\mathrm{C}=\mathrm{C} \text { stretch, Amide I band }(\mathrm{C}=\mathrm{O} \text { stretch coupled to a N-H } \\
\text { bending) }\end{array}$ \\
\hline 12 & - & 2852 & $\mathrm{CH}_{3}$ symmetric stretch of lipids \\
\hline 13 & 2869 & - & $\begin{array}{l}\mathrm{CH}_{2} \text { asym stretches and } \mathrm{CH} \text { stretches in lipids and proteins, } \mathrm{CH}_{2} \\
\text { symmetric stretch of lipids }\end{array}$ \\
\hline 14 & 2919 & - & $\begin{array}{l}\mathrm{CH}_{2} \text { asym stretches and } \mathrm{CH} \text { stretches in lipids and proteins, } \mathrm{CH}_{2} \\
\text { asymmetric stretch of lipids and proteins, } \mathrm{CH}_{3} \\
\text { stretching vibration }\end{array}$ \\
\hline 15 & 2947 & 2950 & $\mathrm{CH}_{3}$ stretching vibrations \\
\hline
\end{tabular}

\subsection{Cell Line Differences Due to Temperature}

The normal temperature of the human cells is constant at $\mathrm{T}=37^{\circ} \mathrm{C}$, so live cell measurements should be performed at this temperature. Unfortunately, we faced two major problems in performing Raman measurements under this temperature. First, due to the long measurement period $(\sim 1 \mathrm{~h})$, the cell's suspension medium (RPMI phenol free medium) began evaporating, and it was impossible to complete a full experiment. Second, live cells were moving from their initial position during each measurement, indicating a movement of more than $50 \%$ of their size.

In order to succeed in acquiring nuclei representative results, we decided to work under a lower sample temperature $\left(15^{\circ} \mathrm{C}\right)$, where both problems were minimized. In particular, the evaporation of the cell's suspension medium was the minimum, with no visible evaporation of the RPMI after $1 \mathrm{~h}$. The temperature of $15^{\circ} \mathrm{C}$ was selected following tests for evaporation and liquidation of the environmental humidity. By maintaining a low temperature, cells were found to be relaxed, probably since they received lower energy amounts from their environment, losing their mobility, which allowed more accurate Raman measurements.

To ensure that this solution of the new temperature of $15^{\circ} \mathrm{C}$ had no potential negative effect in our cell subtype differentiation, in the previously identified Raman spectral characteristics, we performed experiments in six different temperatures ranging from 15 to 
$37^{\circ} \mathrm{C}$ for both cell lines. The identified Raman signal differences were compared with the Raman spectral database to verify that they do not contribute to the cell lines differentiation. Further, bright-field images were acquired before and after each measurement to detect any movements of the cell, or any defocusing due to thermal changes caused by laser absorption from the sample.

As mentioned, the effect of temperature on Raman measurements was tested in both cell lines. The most significant Raman peaks identified that are affected by temperature together with their assignments are presented in the following related tables.

It must be mentioned that in the beginning of the experiments we tried to measure at $\mathrm{T}=15{ }^{\circ} \mathrm{C}$, which proved to be impossible because of the high moisture content of the environment $(54 \%)$ that resulted in liquidation and expansion of the cell suspension. To solve this, we raised the temperature at $\mathrm{T}=18^{\circ} \mathrm{C}$. In other experimental days where humidity was lower $(40 \%)$, we were able to measure at $\mathrm{T}=15{ }^{\circ} \mathrm{C}$. For both temperatures $\left(15\right.$ and $\left.18{ }^{\circ} \mathrm{C}\right)$, a measurement duration of $1.5 \mathrm{~h}$ presented no visual losses on the sample's suspension.

\subsubsection{MDA-V/HL Cell Line Temperature Differences ( $\left.\mathrm{T}_{\mathrm{n}}-\mathrm{T}_{37} \mathrm{MDA}-\mathrm{V} / \mathrm{HL}\right)$}

In Figure 6, the average Raman signal differences $T_{n}-T_{37}$ from all BR3 experiments are presented. In green, the most significant differences with a linear variation versus temperature are identified and depicted.
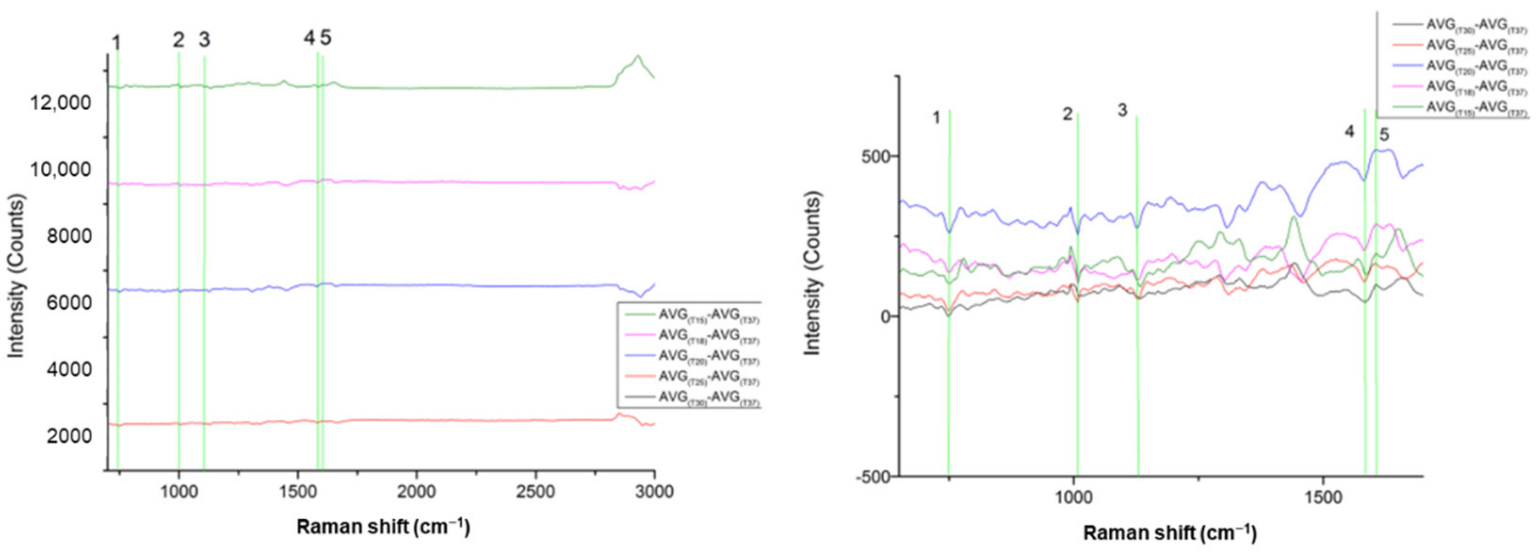

Figure 6. (left) Raman signal differences due to temperature (Tn-T37 plot); (right) Magnification of Raman signal differences.

In Table 5, differences between the identified Raman peaks are presented.

\subsubsection{JMP-1/MCL NHL Cell Line Temperature Differences $\left(T_{n}-T_{37} J M P-1 / M C L ~ N H L\right)$}

In Figure 7 , the average Raman signal differences $T_{n}-T_{37}$ from all BR1, 2 experiments are presented. In green, the most significant differences with a linear variation versus temperature are identified and depicted. 
Table 5. Major Raman peaks found in BR3 under different temperatures. In red color and with an asterisk superscript the temperature dependent Raman peaks are presented.

\begin{tabular}{|c|c|c|}
\hline No & Peaks $\left(\mathrm{cm}^{-1}\right)$ & Assignment \\
\hline $1 *$ & 749 & Symmetric breathing of tryptophan \\
\hline 2 & 1008 & Proteins (L-Serine) [22], Phenylalanine, $v(C-O), v(C-C)$ \\
\hline $3 *$ & $1125-1134$ & $\begin{array}{l}\text { Adenine }\left(1125,1134 \mathrm{~cm}^{-1}[22]\right) \text { and } v(C-N) \text { stretching (lipids, } 1127 \mathrm{~cm}^{-1} \rightarrow \text { proteins), } \\
v(\mathrm{C}-\mathrm{C}) \text { skeletal of acyl backbone in lipid }\left(1129 \mathrm{~cm}^{-1} \rightarrow \text { trans conformation), Phospholipid }\right. \\
\text { structural changes (trans versus gauche isomerism), Acyl chains, Palmitic acid }\end{array}$ \\
\hline $4^{*}$ & $1581-1586$ & DNA/RNA (1586 $\left.\mathrm{cm}^{-1}\right)$, Phenylalanine, hydroxyproline $\left(1582 \mathrm{~cm}^{-1} \rightarrow \mathrm{C}=\mathrm{C}\right.$ stretching $)$ \\
\hline 5 & 1604 & $\begin{array}{l}1600-1800 \mathrm{~cm}^{-1} \rightarrow \text { Amide I band of proteins; due to } \mathrm{C}=\mathrm{O} \text { stretching } \\
\text { Amide I (which is due mostly to the } \mathrm{C}=\mathrm{O} \text { stretching vibrations } \\
\text { of the peptide backbone; has been used the most for structural } \\
\text { studies due to its high sensitivity to small changes in } \\
\text { molecular geometry and hydrogen bonding of peptide group) } \\
1602 \mathrm{~cm}^{-1} \rightarrow \text { Phenylalanine, } \delta(\mathrm{C}=\mathrm{C}) \text {, phenylalanine (protein assignment) } 1603 \mathrm{~cm}^{-1} \rightarrow \\
\mathrm{C}=\mathrm{C} \text { in-plane bending mode of phenylalanine and tyrosine, Ring C-C stretch of } \\
\text { phenyl,1605 } \mathrm{cm}^{-1} \rightarrow \text { Cytosine }\left(\mathrm{NH}_{2}\right)\end{array}$ \\
\hline
\end{tabular}
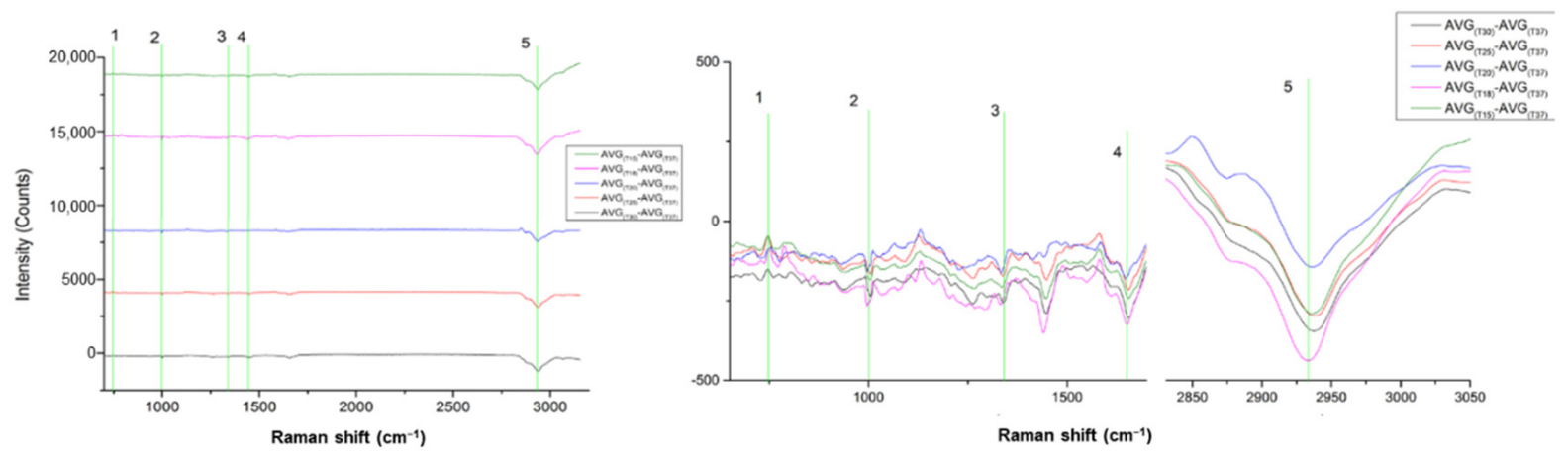

Figure 7. (left) Raman signal differences due to temperature (Tn-T37 plot); (right) Magnification of Raman signal differences.

In Table 6, differences in the identified Raman peaks are presented.

Table 6. Major Raman peaks found in BR1, BR2 under different temperatures. In red color and with an asterisk superscript the temperature dependent Raman peaks are presented.

\begin{tabular}{|c|c|c|}
\hline No & Peaks $\left(\mathrm{cm}^{-1}\right)$ & Assignment \\
\hline 1 * & $745-748$ & $\begin{array}{l}700-745 \mathrm{~cm}^{-1} \rightarrow v(\mathrm{C}-\mathrm{S}) \text { trans (amino acid methionine), } 747 \mathrm{~cm}^{-1} \rightarrow \mathrm{CH}_{2} \text { rocking, } \\
\text { L-Phenylalanine [22], } 748 \mathrm{~cm}^{-1} \rightarrow \mathrm{DNA} \text {, ring breathing of pyrimidine of } \mathrm{T}[23]\end{array}$ \\
\hline 2 & 999-1001 & $\begin{array}{l}999 \mathrm{~cm}^{-1} \rightarrow v_{45}(C-C), \text { observed in the spectra of single human Red blood cell (RBC), } \\
1001 \mathrm{~cm}^{-1} \rightarrow \text { Symmetric ring breathing mode of phenylalanine }\end{array}$ \\
\hline $3 *$ & $1333-1341$ & $\begin{array}{l}\text { Polynucleotide chain }\left(1334 \mathrm{~cm}^{-1} \rightarrow \mathrm{DNA} / \mathrm{RNA} \text { purine bases, Guanine, Adenine), proteins }\right. \\
\left(1337 \mathrm{~cm}^{-1} \rightarrow \text { amide III, } \mathrm{CH}_{2} \text { wagging vibrations from Glycine backbone and proline side }\right. \\
\text { chain, L-Histidine, L-Tryptophane, L-Glutamate), } \mathrm{CH}_{3} \mathrm{CH}_{2} \text { wagging mode of collagen, } \\
\mathrm{CH} \text { protein deformation }\end{array}$ \\
\hline 4 & $1441-1446$ & $\begin{array}{l}1441 \mathrm{~cm}^{-1} \rightarrow \mathrm{CH}_{2} \text { scissoring and } \mathrm{CH}_{3} \text { bending in lipids, Cholesterol and its esters, } \mathrm{C}-\mathrm{H} \\
\text { bending mode of accumulated lipids in the vecrotic core of the atheromatous plaque, } \\
1446 \mathrm{~cm}^{-1} \rightarrow \delta\left(\mathrm{CH}_{2}\right), \delta\left(\mathrm{CH}_{3}\right) \text { protein (collagen) and lipid (phospholipids) assignment } \\
\left(\mathrm{CH}_{2} \text { bending mode being of diagnostic significance), } \mathrm{CH}_{2} \text { deformation }\right.\end{array}$ \\
\hline 5 & 2934 & $\mathrm{CH}_{2}$ asym stretches and $\mathrm{CH}$ stretches in lipids and proteins \\
\hline
\end{tabular}


In all tables, we highlight in red the Raman peaks that were also similar to the Raman peaks found to be contributing to the cell differentiation derived from the PCA analysis. This tells us that the red-highlighted peaks cannot be taken in account for the discrimination of the two cell lines. In contrast, the rest of the Raman peaks are not found in the temperature-based experiments, so they will be considered as significant for the cell type discrimination.

The analysis of the temperature differences between the same cell line showed that there are changes occurring for the Raman peak shifts. In particular, the average Raman spectra from J-MP1 and MDA-V cell lines from all measurements in all temperatures with their standard deviation are presented in Figure S5. Further, in the Tables S2 and S3 (for MDA-V/HL and JMP-1/MCL NHL, respectively), we show the intensity variations versus the temperature changes from the normal temperature of $\mathrm{T}=37^{\circ} \mathrm{C}$. Moreover, Raman peak shifts range is presented in the second line of the tables.

\subsection{Cell Viability}

Based on the overall experiments we performed, we had an average viability of approximately $90 \%$. Cell viability originally was confirmed by cell counting with trypan blue and bright-field images captured the shape and morphology for the two cell lines of our study over experimental time and temperature, monitoring the status of the cells.

During one hour of Raman measurements, the viability of lymphoma cells depended on the temperature that was regulated by Linkam. A significant number of cells at higher temperatures $\left(\mathrm{T}=37^{\circ} \mathrm{C}, \mathrm{T}=30^{\circ} \mathrm{C}\right.$ and $\left.\mathrm{T}=25^{\circ} \mathrm{C}\right)$ were lysed after Raman measurement, in contrast to cells at lower temperatures $\left(\mathrm{T}=20^{\circ} \mathrm{C}, \mathrm{T}=18^{\circ} \mathrm{C} \mathrm{T}=15^{\circ} \mathrm{C}\right)$, which remained alive. We believe that this is due to the fact that, at higher sample temperatures, cells receive higher energy amounts from their environment. This combined with the high energy received from the excitation laser source is above the acceptance threshold of the cells. However, all examined cells considered in this work were alive before and after Raman measurements. Randomly selected cell images after laser irradiation are presented in Figure S6. Generally, we realized that, after $1 \mathrm{~h}$ of measurement at $\mathrm{T}=37^{\circ} \mathrm{C}$, only $10 \%$ of cells were still alive in contrast to $\mathrm{T}=15^{\circ} \mathrm{C}$, where $99 \%$ of cells remained alive. Furthermore, cells did not present any visible damage during the measurements with the high laser illumination (32 $\mathrm{mW}$ for $40 \mathrm{~s}$ ).

\section{Conclusions}

In this work, we show that cell line subtyping can be achieved by means of Raman spectroscopy. Furthermore, in Table 2, we present the Raman peaks that were identified as significant for this purpose.

An efficient and simple Raman spectral measurement methodology is presented that enabled us to achieve fast and robust measurements.

It was shown that temperature affects the Raman spectrum of the cell line nuclei in specific Raman peaks but it did not contribute to cell line differentiation (subtyping).

Results indicate that Raman spectroscopy is a reliable tool for cell line differentiation.

Future work should include a larger sample size for each cell line, as well as multiple other cell lines. The implementation of machine learning algorithms would enable better cell line characterization and possibly identification. This has the potential to lead to faster, better, and earlier lymphoma diagnosis.

Supplementary Materials: The following supporting information can be downloaded at: https: / / www.mdpi.com/article/10.3390/ma15020546/s1, Table S1: Total list of Raman peak assignments. In red color and with an asterisk in superscript the temperature dependent Raman peaks are presented; Figure S1: Demonstration of the Raman spectral background subtraction. Spectra are presented with an offset between them, to allow better visualization of the spectral background changes; Figure S2: PCA of PC1 and PC2 JMP-1/MCL NHL and MDA-V/HL cell lines comparison; Figure S3: PCA of PC1 and PC2 JMP-1/MCL NHL and MDA-V/HL cell lines comparison; Figure S4: Average Raman spectra from BR1 (left) and BR2 (right) (JMP-1/NHL) experiments; Figure S5: Average Raman 
spectra from J-MP1 and MDA-V cell lines from all measurements in all Temperatures. In shadow the related SD of each average is presented; Table S2: Major Raman bands identified as significant under different temperatures for the MDAV/HL cell line. In red color and with a star superscript the temperature dependent Raman peaks are presented; Table S3: Major Raman bands identified as significant under different temperatures for the JMP1/MCL cell line. In red color and with a star superscript the temperature dependent Raman peaks are presented; Figure S6: Randomly selected cell images from bright-field microscope. In the upper and bottom line JMP-1/NHL and MDA-V/HL cell line images are presented respectively, monitoring indistinguishable morphological differences following a successful completion of the measurement.

Author Contributions: Conceptualization and methodology, V.M.P.; bibliographic investigation, K.K., K.P., M.A., G.K. and V.M.P.; experimental characterization and analysis, K.K., K.P., G.K. and V.M.P.; writing-review and editing, K.K. and V.M.P.; supervision, M.A. and V.M.P.; funding acquisition K.P. and V.M.P. All authors have fully read and approved the final version of the manuscript.

Funding: This work was financially supported by the project BIOIMAGING-GR (MIS 5002755) implemented under "Action for Strengthening Research and Innovation Infrastructures," funded by the Operational Programme "Competitiveness, Entrepreneurship and In-novation" (NSRF 2014-2020) and co-financed by Greece and the European Union (European Regional Development Fund) (V.M.P.), and the Stavros Niarchos Foundation within the framework of the project ARCHERS ("Advancing Young Researchers' Human Capital in Cutting Edge Technologies in the field of Systems Biology Approaches and Personal Genomics for Health and Disease Treatment") (K.P. and V.M.P.).

Institutional Review Board Statement: Not applicable.

Informed Consent Statement: Not applicable.

Data Availability Statement: All data are available upon request. The data presented in this study are available on request from the corresponding author.

Acknowledgments: The authors would also like to thank Dimitrios Tsikritsis for the fruitful discussions and his validation of the results and Elias Drakos for providing the cell lines.

Conflicts of Interest: The authors declare no conflict of interest.

\section{References}

1. Steliarova-Foucher, E.; Stiller, C.; Lacour, B.; Kaatsch, P. International Classification of Childhood Cancer, third edition. Cancer 2005, 103, 1457-1467. [CrossRef] [PubMed]

2. Harris, N.L.; Jaffe, E.S.; Diebold, J.; Flandrin, G.; Muller-Hermelink, H.K.; Vardiman, J. Lymphoma classification-From controversy to consensus: The R.E.A.L. and WHO Classification of lymphoid neoplasms. Ann. Oncol. 2000, 11 (Suppl. S1), 3-10. [CrossRef]

3. Caleo, A.; Sanchez-Aguilera, A.; Rodriguez, S.; Dotor, A.M.; Beltran, L.; de Larrinoa, A.F.; Menarguez, F.J.; Piris, M.A.; Garcia, J.F. Composite Hodgkin lymphoma and mantle cell lymphoma: Two clonally unrelated tumors. Am. J. Surg. Pathol. 2003, 27, 1577-1580. [CrossRef]

4. $\quad$ Kramer, S.; Uppal, G.; Wang, Z.X.; Gong, J.Z. Mantle Cell Lymphoma With Hodgkin and Reed-Sternberg Cells: Review With Illustrative Case. Appl. Immunohistochem. Mol. Morphol. 2019, 27, 8-14. [CrossRef] [PubMed]

5. Kuppers, R. The biology of Hodgkin's lymphoma. Nat. Rev. Cancer 2009, 9, 15-27. [CrossRef]

6. Driessen, J.; Visser, O.; Zijlstra, J.M.; Lugtenburg, P.J.; Plattel, W.J.; Kersten, M.J.; Dinmohamed, A.G. Primary therapy and relative survival in classical Hodgkin lymphoma: A nationwide population-based study in the Netherlands, 1989-2017. Leukemia 2021, 35, 494-505. [CrossRef] [PubMed]

7. Jain, P.; Wang, M. Mantle cell lymphoma: 2019 update on the diagnosis, pathogenesis, prognostication, and management. Am. J. Hematol. 2019, 94, 710-725. [CrossRef]

8. Shiramizu, B.; Oda, R.; Kamada, N.; Garcia, M.A.; Shieh, T.; Maeda, T.A.; Choi, S.Y.; Lim, E.; Misra, A. Unique Raman Spectroscopic Fingerprints of B-Cell Non-Hodgkin Lymphoma: Implications for Diagnosis, Prognosis and New Therapies. J. Biol. Med. Sci. 2018, 2, 105. [PubMed]

9. Keshavarz, M.; Tan, B.; Venkatakrishnan, K. Label-Free SERS Quantum Semiconductor Probe for Molecular-Level and in Vitro Cellular Detection: A Noble-Metal-Free Methodology. ACS Appl. Mater. Interfaces 2018, 10, 34886-34904. [CrossRef]

10. Keshavarz, M.; Chowdhury, A.K.M.R.H.; Kassanos, P.; Tan, B.; Venkatakrishnan, K. Self-assembled N-doped Q-dot carbon nanostructures as a SERS-active biosensor with selective therapeutic functionality. Sens. Actuators B Chem. 2020, $323,128703$. [CrossRef]

11. Rau, J.V.; Marini, F.; Fosca, M.; Cippitelli, C.; Rocchia, M.; Di Napoli, A. Raman spectroscopy discriminates malignant follicular lymphoma from benign follicular hyperplasia and from tumour metastasis. Talanta 2019, 194, 763-770. [CrossRef] [PubMed] 
12. Lloyd, G.R.; Orr, L.E.; Christie-Brown, J.; McCarthy, K.; Rose, S.; Thomas, M.; Stone, N. Discrimination between benign, primary and secondary malignancies in lymph nodes from the head and neck utilising Raman spectroscopy and multivariate analysis. Analyst 2013, 138, 3900-3908. [CrossRef] [PubMed]

13. Lin, D.; Lin, J.Q.; Wu, Y.A.; Feng, S.Y.; Li, Y.Z.; Yu, Y.; Xi, G.Q.; Zeng, H.S.; Chen, R. Investigation on the interactions of lymphoma cells with paclitaxel by Raman spectroscopy. Spectrosc. Int. J. 2011, 25, 23-32. [CrossRef]

14. Das, R.S.; Agrawal, Y.K. Raman spectroscopy: Recent advancements, techniques and applications. Vib. Spectrosc. 2011, 57, 163-176. [CrossRef]

15. Leventaki, V.; Drakos, E.; Karanikou, M.; Psatha, K.; Lin, P.; Schlette, E.; Eliopoulos, A.; Vassilakopoulos, T.P.; Papadaki, H.; Patsouris, E.; et al. c-JUN N-terminal kinase (JNK) is activated and contributes to tumor cell proliferation in classical Hodgkin lymphoma. Hum. Pathol. 2014, 45, 565-572. [CrossRef]

16. Talari, A.C.S.; Movasaghi, Z.; Rehman, S.; Rehman, I.U. Raman Spectroscopy of Biological Tissues. Appl. Spectrosc. Rev. 2015, 50, 46-111. [CrossRef]

17. Czamara, K.; Majzner, K.; Pacia, M.Z.; Kochan, K.; Kaczor, A.; Baranska, M. Raman spectroscopy of lipids: A review. J. Raman Spectrosc. 2015, 46, 4-20. [CrossRef]

18. Notingher, I.; Hench, L.L. Raman microspectroscopy: A noninvasive tool for studies of individual living cells in vitro. Expert Rev. Med. Devices 2006, 3, 215-234. [CrossRef]

19. Tsikritsis, D.; Richmond, S.; Stewart, P.; Elfick, A.; Downes, A. Label-free identification and characterization of living human primary and secondary tumour cells. Analyst 2015, 140, 5162-5168. [CrossRef]

20. Lee, L.C.; Liong, C.Y.; Jemain, A.A. Partial least squares-discriminant analysis (PLS-DA) for classification of high-dimensional (HD) data: A review of contemporary practice strategies and knowledge gaps. Analyst 2018, 143, 3526-3539. [CrossRef]

21. Candeloro, P.; Grande, E.; Raimondo, R.; Di Mascolo, D.; Gentile, F.; Coluccio, M.L.; Perozziello, G.; Malara, N.; Francardi, M.; Di Fabrizio, E. Raman database of amino acids solutions: A critical study of extended multiplicative signal correction. Analyst 2013, 138, 7331-7340. [CrossRef] [PubMed]

22. De Gelder, J.; De Gussem, K.; Vandenabeele, P.; Moens, L. Reference database of Raman spectra of biological molecules. J. Raman Spectrosc. 2007, 38, 1133-1147. [CrossRef]

23. Pyrak, E.; Jaworska, A.; Kudelski, A. SERS Studies of Adsorption on Gold Surfaces of Mononucleotides with Attached Hexanethiol Moiety: Comparison with Selected Single-Stranded Thiolated DNA Fragments. Molecules 2019, 24, 3921. [CrossRef] [PubMed]

24. Kelly, J.G.; Najand, G.M.; Martin, F.L. Characterisation of DNA methylation status using spectroscopy (mid-IR versus Raman) with multivariate analysis. J. Biophotonics 2011, 4, 345-354. [CrossRef] [PubMed] 